\title{
Facial Plexiform Neurofibroma excision with sequential muti-layer hemostatic sutures, the novel technique to reduce blood loss
}

\author{
Jonathan Velazquez-Mujica*1, Willerd Cadavid ${ }^{2}$, Andrea DonFrancesco ${ }^{1}$, Dicle Aksoyler ${ }^{1}$, Hung-chi Chen ${ }^{1,3}$ \\ ${ }^{1}$ Department of Plastic Surgery, China Medical University Hospital, Taichung, Taiwan \\ ${ }^{2}$ Department of Plastic Surgery Hospital Calixto Garcia, La Habana Cuba \\ ${ }^{3}$ Profesor of Plastic Surgery and Microsurgery, China Medical University Hospital, Taichung, Taiwan
}

Received: June 19, 2020

Accepted: September 15, $2020 \quad$ Online Published: October 19, 2020

DOI: $10.5430 /$ jst.v10n2p17

URL: https://doi.org/10.5430/jst.v10n2p17

\begin{abstract}
Plexiform neurofibromatosis is an autosomal dominant and is frequently seen at birth. Surgical excision is asociate to facial nerve damage and profussal bleeding. Sequential multi-layered hemostatic sutures is a technique frequently used in our practice for Arterio-veous malfromations (AVM). 15 patiets with facial plexiform neurofibroma were treated from 2004 to 2020 with surgical excision, in all patients the hemifacial area was affected. Although preoperative embolization is well known as a safe technique to reduce intraoperative bleeding, low rates of serious complications were reported as stroke, ischemic attack and necrosis. The multi-layered hemostatic sutures permit to remove piecewise the tumor avoiding dramatically bleeding in all our procedures, and is based on vessel collapse after mechanical ligation. The sequential multi-layer suture and the retrograde disection of the facial nerve in our practice has decresed the average of iatrogenic damage of nerve, and massive bleeding during the excision of the plexiform neurofibroma.
\end{abstract}

Key Words: Plexiform Neurofibroma, Facial Neurofibroma, retrograde facial nerve dissection, nerve tumors, Facial nerve

\section{INTRODUCTION}

Plexiform neurofibromatosis (NF) is characterized by neural tissue hamartomas that grow along nerve sheathh ithin the subcutaneous fat or deeper tissues. There are three types according to morphological differences of Neurofibromatosis type 1; cutaneous, subcutaneous, and plexiform, the last one can be nodular or diffuse. ${ }^{[1]} \mathrm{NF} 1$ is an autosomal dominant trait but half of the affected individuals have a de novo variant. Plexiform neurofibromatosis may cause pain, and can grow until generation of deformities.

Malignant peripheral nerve sheath tumors may occur in $10 \%$ of the afected individuas. ${ }^{[2]}$ Tumors may present in viscera, bone, muscl and underlying fascia. Is frequently seen at birth due to its Autosomal dominant pattern or patients can develop in the first year of life with a rapid growth in childhood. Even though it is generally presented as a soft tumor, it can be felt as firm nodular areas within the tumor, known as a "bag of worms". Surgical excision is associated with facial nerve damage, extensive muscle resection and profusse bleeding. [3]

Sequential multi-layer hemostatic sutures ${ }^{[4]}$ is a technique frequently used in our practice for Arterio-veous malfro-

\footnotetext{
*Correspondence: Jonathan Velazquez-Mujica; Email: drjonathan.vm@gmail.com; Address: Department of Plastic Surgery, China Medical University Hospital, Taichung, Taiwan.
} 
mations (AVM) that facilitates the excision reducing the uncontrollable intra-operative bleeding, we used same technique for excision of plexiform neurofibroma, to control the expected bleeding. The disection is performed under microscope to avoid facial nerve iatrogenic injury ${ }^{[5]}$ with retrograde technique.

We present the combination of these 2 techniques to resection of the plexiform neurofibroma in hemifacial area, when the tumor is affecting only the soft tissue. When it affects the bone some microvascular reconstruction or titanium mesh is associated after multiple resection of the tumor, aesthetic procedure is also freqeuntly performed, procedures that we will not mention in this manuscript.

\section{Patients And methods}

15 patiets with facial plexiform neurofibroma were treated from 2004 to 2020 with surgical excision procedures. The inclusion critera was no malignancies associated with the tumor, major facial plexiform neurofibroma plus minor tumors in other region of the body, and facial plexiform neurofibroma plus large tumors in other region of the body. The other locations included trunk or extremities. All the excisions were planned based on clinical and MRI findings, in all patients the hemifacial area was affected, some patients were refered to our department after local procedures not performed by our staff. The Facial nerve functions preoperatively and postoperatively were evaluated according to House-Brackmann classification and the findings were classified according to the function of the affected area including Forehead, Eye and Mouth and the classification of each area were between grade II. Mild dysfunction and grade V. Severe dysfunction. The age range was between 3 years old and 45 years old 9 male and 6 female. All patient were followed at least for 10 years according to the age of resection.

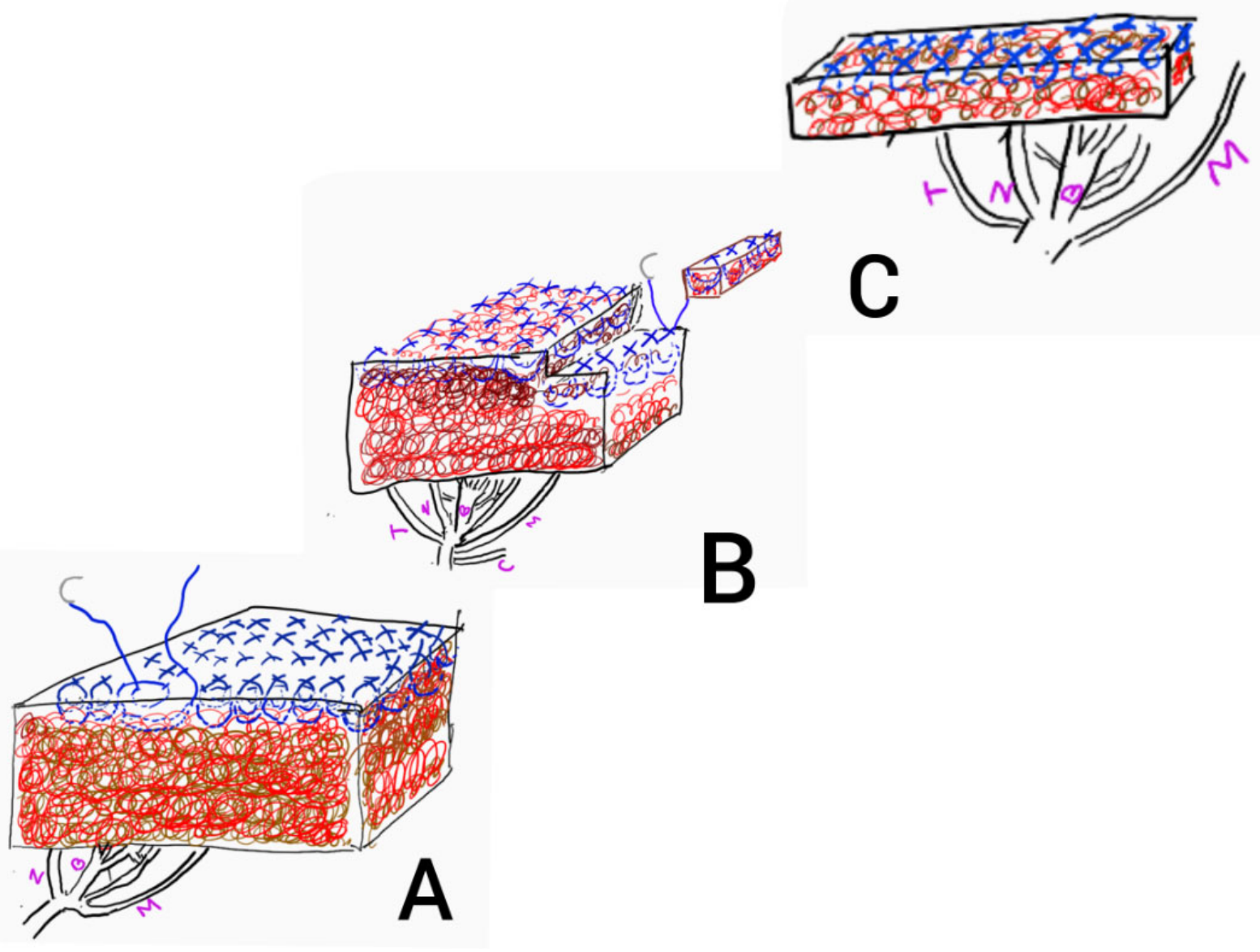

Figure 1. facial nerve branches under the plexiform neurofibroma, T: Temporal branch, Z: Zygomatic Branch, B: Bucal branch, M: Marginal mandibular branch, C: Cervical branch 1A. hemostatic suture placed (blue sutured). 1B. Piece by piece removed of tumor, and new sutures placed on the raw face of the tumor, depth control $0.5-1 \mathrm{~cm}$ average $1 \mathrm{C}$ : Marginal mandibular branch without tumor above, and tumor debulked above other branches. 


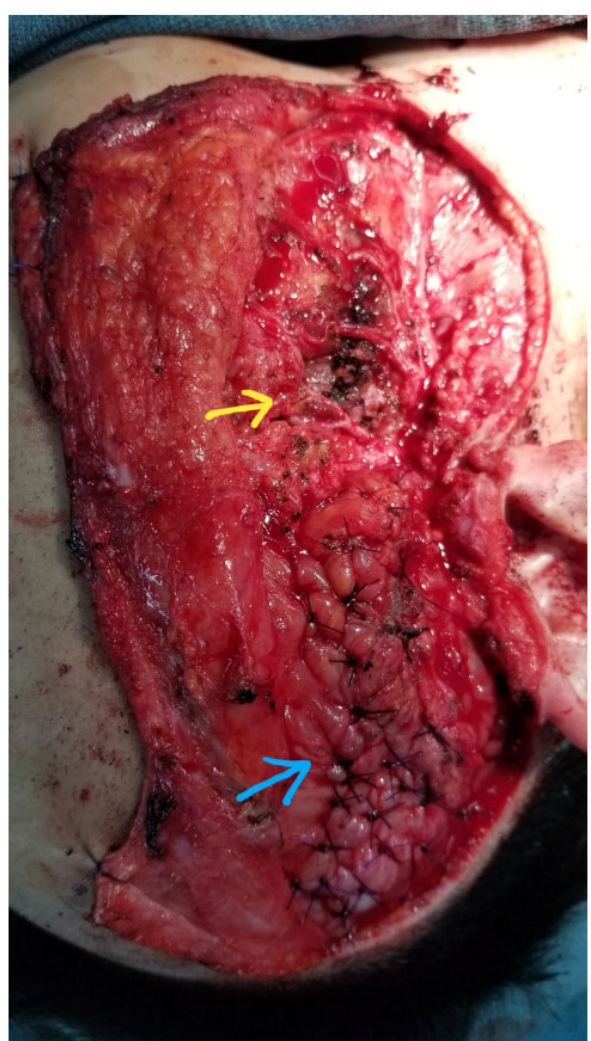

Figure 2. Blue arrow show hemostatic sutures placed, yellow arrow pointed to facial nerve preserved after piece of tumor removed above the nerve

\section{Surgical TehCNIQUE}

The skin incision started at preauricular regions, it could be extended cephalad in the hairline or back to hairline depending on the affected areas. After the incision continued to internal margin of the tragus until reaching the ear lobe, it continued posteriorly $1 \mathrm{~cm}$ to $2 \mathrm{~cm}$ on the mastoid process and ran down to the inferior border of the mandible $4 \mathrm{~cm}$ to $7 \mathrm{~cm}$. The incision extended on the inferior border of the mandible and the skin flap started to be elevated subdermal very carefully due to the profuse bleeding of the tumor, when it ocurred during elevation of the skin flap gentle pressure was made with wet gauze and tumescent preparation for few minutes. Under the microscope the disection started from the facial atery to identified the marginal mandibular branch of the facial nerve that crosses the anterior facial artery, and is the land mark of our plane of disection. We continued in a retrograde disection of the facial nerve from tumor and all the tissue above the branches started to be removed piece by piece after several hemostatic sutures with 3-0 PDSTM that were placed through the superficial layers of the tumor controlling the depth of the suture no more than $0.5 \mathrm{~cm}$ to $1 \mathrm{~cm}$ (see Figure 1A), taking care of the sutures not going under our plane of disection that is marked by the plane of the fa- cial nerve branch, the hemostatic suteres were always placed parallel to the axial road of the nerve branches to not trap it with the suture. After we removed some pieces of the tumor with electrocautery, new hemostatic sutures were placed on the raw face following the same technique controlling the depth of the suture (see Figure 1B) until debulking all the tumor and all branches of the facial nerve were isolated in a retrograde disection until the main trunk was exposed (see Figure 1C and 2).

The tumor under the facial nerve branches was removed after elevating the nerve branches and some part of the facial muscle were removed (masseter, risorious, zygomatic major and minor, or temporal muscle) if it was required (see Figure 3). Some of the network interconnections between zygomatic and buccal branch were removed, but always preserving the main branch. Nerve stimulator was used in some cases, and land markers with prolene or nylon 5-0 and hemoclip to tie the land marker suture for easy recognition and tracing in the next procedure. Buccal fat was partially removed in most of the cases, to improve the symmetry with contralateral side. Hemostatic suteres can be preserved for further procedures.

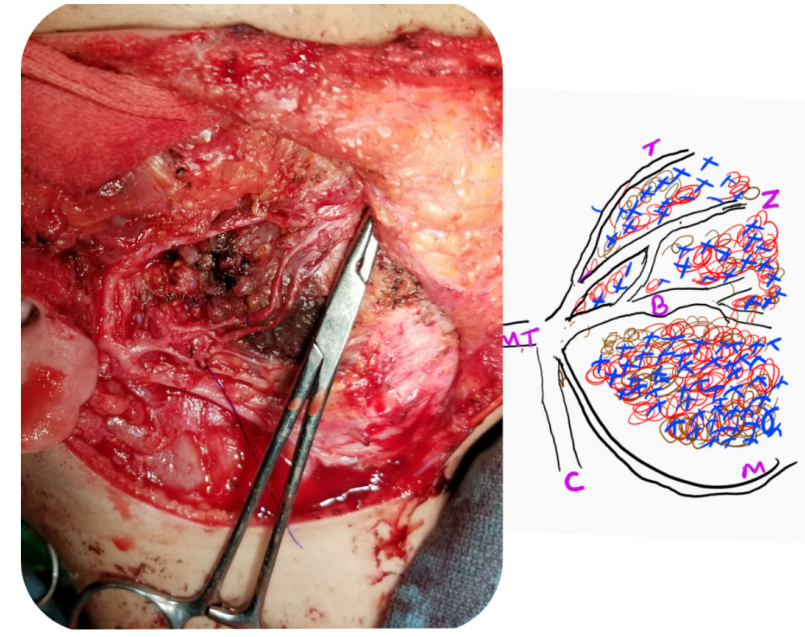

Figure 3. Facial nerve exposition after plexiform neurofibroma resection above and under the nerve branches, including some pieces of muscle affected by the tumor

Suction drains were placed and the skin incision was closed by planes, and some skin resection was needed. Few procedures were perfomed under hypotensive anesthesia. Variations on the incision size and other incision were associated depending on the patient's necessity and affected area. Subsequent procedures have been perfomed, and aesthetic procedures and microvascular reconstruction were added when it was needed. Subsequent procedures can be perfomed after 6 months. 


\section{Results}

The blood loss range during the major excision of facial tumor was $120 \mathrm{ml}$ to $1,800 \mathrm{ml}$. 12 patients received blood transfussion the in a range of 1 to 7 depending of the blood loss calculated during the major surgery. During the minor procedures blood transfission was not needed.

On average 1 major surgery was performed and 4 to $5 \mathrm{mi}$ nor revision surgeries were required to removed the tumor gradually, according to the size and regrowth of the tumor.

2 patients had a surgery before and were sent to our department due to overgrowth of the tumor and severe deformity of the affected side. The complications were: 1 patient suffered wound dehiscence; 3 patients suffered hematoma and were treated conservatively, no needed re-exploration.

The facial nerve damage reported before surgery did not recover in all patients. However, 2 patients after surgery increased the facial weakness in zygomatic-buccal branches and 2 presented nose deviation.

In the minor revision surgeries procedures to recover the affected muscle facial functions affected were perfomed.

\section{Discussion}

Neurofibromatosis type I or von Recklinghausen disease is an autosomal dominant disorder with mutation on the long arm of chromosome 17 (17q11.2). ${ }^{[6]}$ and is associated with multiple neoplasm, including sheath tumors, myelogenous leukemia, pheochromocytoma and neurofibromas. ${ }^{[7]}$ hemifacial neurofibroma has a great impact on emotional and self esteem due to the social stigma, the resection of the tumor can improve quality of life. The tumor can occur anywhere along the nerve, can involve orbit and occular globe, ${ }^{[8]}$ face and upper cervical nerves. Indications for surgery include: function compromised, intractable pain, malignant transformation, severely disfiguring, or progressive enlargement with compressive nerve effects.

Plexiform neurofibroma features is characterized by a large tumor that develops hemifacial disfiguration. Resection in pediatric patient is frequently associated with recurrence in $20 \%$, and incomplet resection had a recurrence in up to $45 \%$ of the cases, Acording to Needle MN. ${ }^{[9]}$ The surgical treatment is potential for haemorrahge due to extremely friability of the blood vessels caused by myxomatous degeneration, the abnormal vascularization of the tumor along with the nerual tissue is frequently observed as a arteriovenous fistula and aberrant large feeder infiltrative vessels known as hemangioneurofibroma. ${ }^{[10,11]}$

Although preoperative embolization is well known as a safe technique to reduce intraoperative bleeding, low rates of serious complications were reported as stroke, ischemic attack and necrosis. ${ }^{[12,13]}$ and is not recommended as a single treatment due to the continuing growth of the tumor and its neovascularization. Hypotensive anesthesia and infiltration of tumescent fluid are effective in decreasing the intraoperative bleeding. ${ }^{[14,15]}$ The multi-layered hemostatic sutures permit to remove piecewise the tumor avoiding profuse bleeding in all our procedures, and is based on vessel collapse after mechanical ligation, ${ }^{[4]}$ from the superficial surface to deep layers, preserving the vital structures. The stitches placed parallel to the axial pattern of the nerve branches and controlling the depth of the stitch superficial to our plane of disection makes sure that we do not trap the facial nerve branches nevertheless, some of the network interconnection between the zygomatic and buccal branch can be trapped by the suture, without affecting the facial expression. ${ }^{[16]}$ However multiple procedures were associated to our technique. Eventhough hypotensive ansthesia were requered in some cases, in all procedures tumescent preparation were required for wet gauzes with gentle compression. The temporary facial paralysis after surgery or some branches are associated with the surgery but also with the tumor before the excision, but to minimize the iatrogenic damage rate for the procedure we perform the procedure under microscope.

\section{Conclusion}

The sequential multi-layered suture and the retrograde disection of the facial nerve in our practice has decresed the average of iatrogenic damage of nerve, and massive bleeding during the excision of the plexiform neurofibroma. The disection under microscope helps to identified our plane of disection and the excision between the brances of nerve and under the nerve including partial excision of the masseter, risorious, zygomatic major and minor or temporal muscle. Leaving hemostatic sutures in the tumor helps to keep the collapse of the vessels for the next procedure.

\section{CONFlicts of INTEREST Disclosure}

The authors declare no conflict of interest

\section{REFERENCES}

[1] Jayachandran D, Sunantha S, Gopalaiah H, et al. Plexiform Neurofibromatosis involving face and oral cavity. J Oral Maxillofac Pathol 2014; 18(1): 114-7. PMid:24959050. https://doi .org/10.410
3/0973-029X. 131932

[2] Evans DG, Baser Me, McGaughran J, et al. Malignant peripheral nerve sheat tumors in neurofibormatosis 1 - J Med Genet. 2002; 39: 311-314. PMid:12011145. https://doi.org/10.1136/jmg. 39 


\section{.5 .311}

[3] Vasanth S, Kotamarti BS, Adam M, et al. Large Neurofibroma of the face. Eplasty. 2015; 15: ic36.

[4] Lim SY, Sze WMY, Constantinides J, et al. Sequential multi-layerd hemosatic sutures for stepwise removal of arteriovenous malformatios: the pienaple technique. J Plast Reconstr Aesthet Surg. 2014 Apr; 67(4): 581-2. PMid:24268693. https ://doi.org/10.1016/ j.bjps. 2013.10.043

[5] Nicoli F, D'Ambrosia C, Lazzeri D, et al. Microsurgical disection of facial nerve in parotidectomy: a discussion of techniques and longterm results. Gland Surg. 2017 Aug; 6(4): 308-314. PMid:28861369. https://doi.org/10.21037/gs.2017.03.12

[6] Friedman JM, Arbiser J, Epstein JA, et al. Cardiovascular disease in neurofibromatosis 1: report of the NF Cardiovascular task force. Genet Med. 2002; 4: 105-111. PMid:12180143. https://doi .or g/10.1097/00125817-200205000-00002

[7] Rasmussen SA, Yang Q, Friedman JM. Mortality in neurofibromatosis 1: an analysis using U.S. Death certificates. Am J Hum Genet. 2001; 68: 1110-1118. PMid:11283797. https ://doi.org/10.1 $086 / 320121$

[8] Milburn J, Gimenez C, Dutweiler E. Clinical Images:Imaging Manifestations of Orbital Neurofibromatosis Type 1.

[9] Needle MN, Cnaan A, Dattilo J, et al. Prognostic signs in the surgical manegement of plexiform neurofibroma: The children's hospital of Phildelphia experience, 1974-1994. J Pediatr. 1997; 131: 678-682. https ://doi.org/10.1016/S0022-3476(97)70092-1

[10] Mukherji MM. Giant Neurfibroma of the head and neck. Plast Reconst Surg. 1974; 59: 984.
[11] Littlewood AH, Stilwell JH. The vascular features of plexiform neurofibroma with some observations on the importance of pre-operative angiography and the value of pre.operative intra -arterial embolisation. Br J Plast Surg. 1983; 36(4): 501-506. https ://doi .org/10 .1016/0007-1226(83) 90140-6

[12] Nair S, Gobin YP, Leng LZ, et al. Preoperative embolization of hypervascular thoracic, lumbar, and sacral spinal column tumors: technique and outcomes from a single center. Interv Neuroradiol. 2013; 19: 377-385. PMid:24070089. https://doi.org/10.117 $7 / 159101991301900317$

[13] Moore JR, Weiland AJ. Embolotherapy in the treatment of congenital arteriovenous malformations of the hand: a case report. J Hand Surg [Am]. 1985; 10A: 135-9. https://doi.org/10.1016/S0363-5 023 (85) $80265-3$

[14] Tung TC, Chen YR, Chen KT, et al. Massive intratumor hemorrhage in facial plexiform neurofibroma. Heand and neck. 1997; 19: 15862. https : //doi .org/10.1002/(SICI) 1097-0347(199703) 1 $9: 2<158:$ : AID-HED13>3.0.CO ; 2-9

[15] Hivelin M, Wolkenstein P, Lepage C, et al. Facial Aesthetic unit remodeling procedure for neurofibromtosis type 1 hemifacial hypertrophy: report on 3 consecutive adult patients. Plast Reconstr Surg. 2010; 125: 1197-207. PMid:20335870. https://doi.org/10.1 097/PRS . 0b013e3181d180e9

[16] Dhiwakar M, Khan Z. Sacrifacing the buccal branch of the facial nerve during parotidectomy: Buccal nerve sacrifice in parotidectomy. Head and neck. 2016; 38(12): 1821-1825. PMid:27248506. https://doi.org/10.1002/hed. 24514 